\title{
MATRIKS KETERHUBUNGAN LANGSUNG TOPOLOGI HINGGA
}

\author{
Dewi Sukriyah \\ PENIDIKAN MATEMATIKA STKIP PGRI SIDOARJO \\ ryaitusukriyah@gmail.com
}

\begin{abstract}
Abtrak:
Topologi merupakan cabang ilmu matematika yang mempelajari suatu struktur yang terdapat pada himpunan. Seperti halnya himpunan hingga yang memiliki kardinalitas, maka topologi hingga juga memiliki kardinalitas. Jika himpunan $S^{S}$ memiliki kardinalitas $n$ dan $\mathcal{T}$ topologi pada $S$, maka kardinalitas dari $\mathcal{T}$ yang dinotasikan dengan $|\mathcal{T}|$ menyetakan banyaknya elemen dari $\mathcal{T}$. Jika $\mathcal{T}$ topologi pada $S$, maka matriks keterhubungan langsung topologi $\mathcal{T}$ adalah matriks berukuran $n \times n$ yang dinotasikan dengan $M(\mathcal{T})$. Matriks $M(\mathcal{T})$ merupakan matriks yang elemennya 0 atau 1.
\end{abstract}

Kata Kunci: Himpunan, Kardinalitas, Matriks Keterhubungan Langsung, Topologi.

\begin{abstract}
:
Topology is a branch of mathematics which study structures on a set. As a finite set, a finite topology have a cardinality. Let $S$ be a finite set with cardinality $n$ and let $\mathcal{T}$ be a topology on $S$, then the cardinality of $\mathcal{T}$ which denotes $|\mathcal{T}|$ is the number of elements $\mathcal{T}$. If $\mathcal{T}$ topology on $S$, then the corresponding matrix to a topology $\mathcal{T}$ is a matrix $n \times n$ which denoted by $M(\mathcal{T}) . M(\mathcal{T})$ is the matrix have element 0 or 1 .

Keywords: Cardinality, Set, The Corresponding Matrix, Topology,
\end{abstract}

\section{PENDAHULUAN}

Topologi merupakan salah satu cabang ilmu matematika yang mempelajari tentang struktur suatu himpunan tak kosong. Suatu topologi pada himpunan tak kosong $S$ adalah suatu koleksi himpunan $\mathcal{T}$ dari himpunan bagian $S$ yang memenuhi: (i) $\varnothing \in \mathcal{T}$ dan $S \in \mathcal{T}$; (ii) jika $A_{i} \in \mathcal{T}$ untuk setiap $i \in I$, maka $\cup_{i \in I} A_{i} \in \mathcal{T}$ dengan $I$ himpunan indeks (hingga atau tak hingga); (iii) jika $A_{i} \in \mathcal{T}$ untuk setiap $i \in I$, maka $\cap_{i \in I} A_{i} \in \mathcal{T}$ dengan $I$ himpunan indeks hingga. Kemudian himpunan $S$ dengan suatu topologi $\mathcal{T}$ yang telah ditentukan disebut ruang topologi dan dinotasikan $(S, \mathcal{T})$, setiap anggota topologi $\mathcal{T}$ merupakan himpunan terbuka ( Juniati, 2003).

Apabila $\mathcal{T}$ suatu topologi hingga, maka $\mathcal{T}$ memiliki kardinalitas (Jr. H. Sharp, 1968). Hal ini karena jumlah anggota dari suatu topologi hingga dapat ditentukan sehingga sebarang topologi hingga memiliki kardinalitas. Kardinalitas suatu topologi dapat juga diketahui melalui matriks keterhubungan langsung dari suatu topologi (Jr. H. Sharp, 1968). 
Artikel ini akan mengkaji tentang kardinalitas topologi hingga melalui matriks keterhubungan langsung topologi hingga beserta sifat-sifat yang terkait yang mengacu pada kajian Rainer Parchmann pada tahun 1974 dengan menambahkan bukti dari teorema-teorema yang di bahas.

\section{HASIL DAN PEMBAHASAN}

Suatu himpunan terdapat sebuah struktur yang sering disebut sebagai ruang topologi. Jika himpunan tersebut hingga misal himpunan $S=\left\{S_{1}, S_{2}, \ldots, S_{n}\right\}$, maka himpunan $S$ memiliki kardinalitas $" n$ " dan topologi yang didefinisikan pada $S$ juga memiliki kardinalitas. Pada bagian ini akan dibahas mengenai kardinalitas suatu topologi yang didefinisikan pada himpunan $S$, matriks keterhubungan langsung topologi dan teorema-teorema yang berhubungan.

\section{Definisi 1}

Diberikan hmpunan hingga $S$ dengan kardinalitas $n$. Jika $\mathcal{T}$ topologi pada $S$, maka kardinalitas dari $\mathcal{T}$ yang dinotasikan dengan $|\mathcal{T}|$ menyatakan banyaknya elemen dari $\mathcal{T}$.

\section{Contoh 1}

Diberikan himpunan hingga $S$ dengan kardinalitas $n$ dan $\mathcal{T}$ topologi pada $S$.

- Jika $\mathcal{T}$ topologi diskrit, maka $|\mathcal{T}|=2^{n}$

- Jika $\mathcal{T}$ topologi indiskrit, maka $|\mathcal{T}|=2$

Berdasarkan definisi tersebut, akan muncul pertanyaan bagaimana kardinalitas topologi pada himpunan $S$ apabila topologinya selain topologi diskrit dan indiskrit. Untuk menjawab pertanyaan tersebut maka terlebih dahulu didefinisikan matriks keterhubungan langsung topologi dari himpunan hingga $S$.

\section{Definisi 2}

Diberikan himpunan hingga $S=\left\{S_{1}, S_{2}, \ldots, S_{n}\right\}$. Jika topologi $\mathcal{T}$ pada $S$, maka matriks keterhubungan langsung topologi $\mathcal{T}$ adalah matriks berukuran $n \times n$ yang dinotasikan $M(\mathcal{T})$, dengan $M(\mathcal{T})=\left[t_{i j}\right]$ dan $t_{i j}=\left\{\begin{array}{c}1, \quad \text { jika } s_{j} \in\left\{s_{i}\right\}^{-} \\ 0, \text { untuk yang lainnya }\end{array}\right.$ untuk setiap $i, j \in\{1,2,3, \ldots, n\}$.

$\left\{s_{i}\right\}^{-}$merupakan himpunan tertutup terkecil yang memuat $s_{j}$ (closure dari $\left\{s_{i}\right\}$ ). 


\section{Contoh 2}

Diberikan himpunan hingga $S=\{a, b\}$ dan $\mathcal{T}$ topologi pada $S$ dengan $\mathcal{T}=\{S, \emptyset,\{a\},\{b\}\}$ dan $|\mathcal{T}|=$ 4. Maka himpunan tertutup pada $\{S, \mathcal{T}\}$ adalah $S, \emptyset,\{a\},\{b\}$ dan $\{a\}^{-}=\{a\},\{b\}^{-}=\{b\}$, dan $S^{-}=S$.

Sehingga diperoleh matriks keterhubungan langsung topologi $\mathcal{T}$ dengan $M(\mathcal{T})=\left[\begin{array}{ll}1 & 0 \\ 0 & 1\end{array}\right]$.

Hubungan baris dan kolom pada matriks $M(\mathcal{T})$ adalah sebagai berikut:

1. Baris ke-i dari $M(\mathcal{T})$ menyatakan fungsi karakteristik closure dari $\left\{s_{i}\right\}$ pada $\mathcal{T}$.

Bukti:

Berdasarkan Definisi 2, $\left\{s_{i}\right\}^{-}$merupakan himpunan tertutup terkecil yang memuat $s_{i}$,

$t_{i j}=\left\{\begin{array}{l}1, \quad \text { jika } s_{j} \in\left\{s_{i}\right\}^{-} \\ 0, \text { untuk yang lainnya }\end{array}\right.$ untuk setiap $i, j \in\{1,2, \ldots, n\}$

Karena yang akan diperhatikan baris ke- $i$ maka $j \in\{1,2, \ldots, n\}$

Berdasarkan (*) dan (**) maka baris ke-i merupakan karakteristik untuk closure dari $\left\{S_{i}\right\}$.

2. Kolom ke-j dari $M(\mathcal{T})$ menyatakan fungsi karakteristik untuk himpunan terbuka terkecil $B_{j}$ yang memuat $s_{j}$.

Bukti:

Diberikan $B_{j}$ merupakan himpunan terbuka terkecil yang memuat $s_{j}$.

Akan dibuktikan bahwa jika $s_{j} \in\left\{s_{i}\right\}^{-}$maka $s_{i} \in B_{j}$. Andaikan $s_{i} \notin B_{j}$, maka $s_{i} \in B_{j}^{c}$. Karena $B_{j}$ himpunan terbuka maka $B_{j}^{c}$ himpunan tertutup dan $\left\{s_{i}\right\}^{-} \subset B_{j}^{c}$. Terjadi kontradiksi, maka pengandaian salah. Sehingga, jika $s_{j} \in\left\{s_{i}\right\}^{-}$maka $s_{i} \in B_{j}$.

Jadi terbukti bahwa kolom ke-j dari $M(\mathcal{T})$ menyatakan karateristik untuk himpunan terbuka terkecil $B_{j}$ yang memuat $s_{j}$.

\section{Teorema 1}

Jika $M(\mathcal{T})=\left[t_{i j}\right]$ merupakan matriks keterhubungan langsung topologi $\mathcal{T}$ jika dan hanya jika memenuhi:
1. $t_{i j}=1$ atau 0
2. $t_{i i}=1$
3. $M(\mathcal{T})^{2}=M(\mathcal{T})$

\section{Bukti:}

- Bukti ke kanan

Diberikan $M(\mathcal{T})=\left[t_{i j}\right]$ matriks keterhubungan langsung topologi $\mathcal{T}$. Maka berdasarkan Definisi 2, entri-entri $M(\mathcal{T})$ memenuhi $t_{i j}=1$ atau 0 . 
Karena pada suatu ruang topologi, suatu himpunan pasti termuat pada closurenya dan berdasarkan

Definisi 2, maka entri-entri diagonal utama dari $M(\mathcal{T})$ adalah 1 sehingga memenuhi $t_{i i}=1$.

$M(\mathcal{T})^{2}=M(\mathcal{T}) M(\mathcal{T})=\left[c_{i j}\right] ; i, j \in\{1,2, \ldots, n\}, \quad M(\mathcal{T})$ merupakan matriks keterhubungan

langsung topologi $\mathcal{T}$.

Berdasarkan Definisi 2, $M(\mathcal{T})$ matriks yang merepresentasikan relasi $R \subset S \times S$ dengan $\left(s_{i}, s_{j}\right) \in$ $R$ jika dan hanya jika $s_{j} \in\left\{s_{i}\right\}^{-}$.

Berdasarkan definisi komposisi relasi, diperoleh $R \circ R=R_{1}$ merupakan relasi $R_{1} \subset S \times S$ dengan $\left(s_{i}, s_{j}\right) \in R_{1}$ jika dan hanya jika $s_{j} \in\left\{s_{i}\right\}^{--}$.

Matriks relasi $R_{1}$ dapat diperoleh dari hasil kali $M(\mathcal{T}) M(\mathcal{T})=\left[c_{i j}\right]$ dengan aritmetika Boolean.

$\left[c_{i j}\right]$ matriks relasi $R_{1}$, sehingga diperoleh:

$c_{i j}=\left\{\begin{array}{c}1, \quad \text { jika } s_{j} \in\left\{s_{i}\right\}^{-} \\ 0, \text { untuk yang lainnya }\end{array}\right.$ untuk setiap $i, j \in\{1,2, \ldots, n\}$

Akan ditunjukkan $c_{i j}=t_{i j}$ untuk suatu $i, j \in\{1,2, \ldots, n\}$.

Jika $s_{j} \in\left\{s_{i}\right\}^{-}$maka $s_{j} \in\left\{s_{i}\right\}^{--}$karena $\left\{s_{i}\right\}^{-} \subset\left\{s_{i}\right\}^{--}$sehingga $c_{i j}=t_{i j}$ untuk suatu $i, j \in\{1,2, \ldots, n\}$. Jadi, $M(\mathcal{T})^{2}=M(\mathcal{T})$.

- Bukti ke kiri

Diberikan $M(\mathcal{T})=\left[t_{i j}\right]$ matriks persegi dengan $t_{i j}=1$ atau $0, t_{i i}=1$, dan $M(\mathcal{T})^{2}=M(\mathcal{T})$. Maka berdasarkan Definisi 2, diperoleh $t_{i j}=1$ artinya $s_{j} \in\left\{s_{i}\right\}^{-} ; t_{i j}=0$ artinya $s_{j} \notin\left\{s_{i}\right\}^{-} ; t_{i i}=1$ artinya $s_{j} \in\left\{s_{i}\right\}^{-} ; M(\mathcal{T})^{2}=M(\mathcal{T})$ artinya $A^{--}=A^{-}$, untuk setiap $A \subset S$.

$M(\mathcal{T})$ merupakan matriks keterhubungan langsung topologi $\mathcal{T}$.

Pada teorema 1, syarat 1 menyebabkan $M(\mathcal{T})$ bersifat refleksif dan syarat 2 menyebabkan $M(\mathcal{T})$ bersifat transitif.

\section{Teorema 2}

Diberikan $\mathcal{T}^{\prime}$ suatu topologi pada himpunan hingga $S^{\prime}=\left\{S_{1}, S_{2}, \ldots, S_{n-1}\right\}$ maka terdapat topologi $\mathcal{T}_{1}$ dan $\mathcal{T}_{2}$ pada $S=S^{\prime} \cup\left\{S_{n}\right\}$ yang kardinalitasnya memenuhi:

1. $\left|\mathcal{T}_{1}\right|=\left|\mathcal{T}^{\prime}\right|$

2. $\left|\mathcal{T}_{2}\right|=\left|\mathcal{T}^{\prime}\right|+1$

Jika $n=r+t, \mathcal{T}^{\prime}$ merupakan topologi pada himpunan yang kardinalitasnya $r$ dan $\mathcal{T}^{\prime \prime}$ merupakan topologi pada himpunan yang kardinalitasnya $t$ maka terdapat topologi $\mathcal{T}_{3}$ pada $S$ yang kardinalitasnya memenuhi:

3. $\left|\mathcal{T}_{3}\right|=\left|\mathcal{T}^{\prime}\right|\left|\mathcal{T}^{\prime \prime}\right|$ 


\section{Bukti:}

Misalkan himpunan hingga $S^{\prime}=\left\{s_{1}, S_{2}, \ldots, S_{n-1}\right\}, \mathcal{T}^{\prime}$ topologi pada $S^{\prime}$ dengan $M\left(\mathcal{T}^{\prime}\right)=\left[t^{\prime}{ }_{i j}\right], i, j \in$ $\{1,2, \ldots, n-1\}$ dan $S=S^{\prime} \cup\left\{S_{n}\right\}$.

1. Akan dibuktikan: Ada topologi $\mathcal{T}_{1}$ pada $S$ dengan $\left|\mathcal{T}_{1}\right|=\left|\mathcal{T}^{\prime}\right|$

Bukti:

Karena $S=S^{\prime} \cup\left\{S_{n}\right\}$ himpunan tak kosong, maka $S$ memiliki himpunan bagian berupa himpunan kosong dan himpunan tak kosong serta dapat di definisikan suatu topologi pada $S$. Didefinisikan $T_{1}=\left[\begin{array}{ccc}M\left(\mathcal{J}^{\prime}\right) & \ldots & t_{1 n} \\ \vdots & \vdots & \vdots \\ t_{n 1} & \ldots & t_{n n}\end{array}\right]$ matriks berukuran $n \times n$, dengan

$$
\begin{gathered}
t_{i n}=t^{\prime}{ }_{i(n-1)}^{\prime} \\
t_{n i}=t_{(n-1) i}^{\prime} \\
t_{n n}=1
\end{gathered}
$$

Karena $M\left(\mathcal{T}^{\prime}\right)=\left[t^{\prime}{ }_{i j}\right]$ merupakan matriks keterhubungan langsung topologi $\mathcal{T}^{\prime}$ maka berdasarkan teorema $1, M\left(\mathcal{T}^{\prime}\right)$ refleksif dan $M\left(\mathcal{T}^{\prime}\right)^{2}=M\left(\mathcal{T}^{\prime}\right)$, maka $T_{1}$ memenuhi $T_{1}^{2}=T_{1}$. Sehingga dapat dikatakan bahwa $T_{1}$ matriks keterhubungan langsung topologi $S$.

Diambil $T_{1}=M\left(\mathcal{T}_{1}\right)$, karena $T_{1}$ matriks keterhubungan langsung topologi $S$, maka $M\left(\mathcal{T}_{1}\right)$ matriks keterhubungan langsung topologi $\mathcal{T}_{1}$ pada $S$. Jadi, ada topologi $\mathcal{T}_{1}$ pada $S$.

Karena $M\left(\mathcal{T}^{\prime}\right)$ matriks keterhubungan langsung topologi $\mathcal{T}^{\prime}$ dan $M\left(\mathcal{T}_{1}\right)$ matriks keterhubungan langsung topologi $\left(\mathcal{T}_{1}\right)$, maka terdapat korespondensi satu-satu antara elemen $\mathcal{T}^{\prime}$ dengan elemen $\mathcal{T}_{1}$ sehingga kedua topologi tersebut memiliki jumlah elemen yang sama. Jadi, $\left|\mathcal{T}_{1}\right|=\left|\mathcal{T}^{\prime}\right|$

2. Akan dibuktikan: Ada topologi $\mathcal{T}_{2}$ pada $S$ dengan $\left|\mathcal{T}_{2}\right|=\left|\mathcal{T}^{\prime}\right|+1$

Bukti:

Karena $S=S^{\prime} \cup\left\{S_{n}\right\}$ himpunan tak kosong, maka $S$ memiliki himpunan bagian berupa himpunan kosong dan himpunan tak kosong dan dapat didefinisikan suatu topologi pada $S$.

Didefinisikan $T_{2}=\left[\begin{array}{ccc}M\left(\mathcal{T}^{\prime}\right) & & 0 \\ & & \vdots \\ 1 & \ldots & 1\end{array}\right]$ matriks berukuran $n \times n$.

Karena $M\left(\mathcal{T}^{\prime}\right)$ merupakan matriks keterhubungan langsung topologi $\mathcal{T}^{\prime}$ maka berdasarkan teorema $1, M\left(\mathcal{T}^{\prime}\right)$ refleksif dan $M\left(\mathcal{T}^{\prime}\right)^{2}=M\left(\mathcal{T}^{\prime}\right)$, maka $T_{2}$ seperti yang sudah di definisikan memenuhi Teorema 1 dan $T_{2}$ matriks keterhubungan langsung topologi $S$.

Diambil $T_{2}=M\left(\mathcal{T}_{2}\right)$, maka $M\left(\mathcal{T}_{2}\right)$ matriks keterhubungan langsung topologi $\mathcal{T}_{2}$ pada $S$. Jadi, ada topologi $\mathcal{T}_{2}$ pada $S$. 
Karena $M\left(\mathcal{T}_{2}\right)$ matriks keterhubungan langsung topologi $\mathcal{T}_{2}$ maka setiap kolom $M\left(\mathcal{T}_{2}\right)$ merupakan fungsi karakteristik himpunan terbuka terkecil $B_{j}$ yang memuat $s_{j}$, untuk setiap $s_{j} \in S$. Sehingga banyaknya elemen $\mathcal{T}_{2}$ sama dengan banyaknya elemen $\mathcal{T}^{\prime}$ ditambah 1 . Jadi, $\left|\mathcal{T}_{2}\right|=\left|\mathcal{T}^{\prime}\right|+1$

3. Akan dibuktikan: Ada topologi $\mathcal{T}_{3}$ pada $S$ dengan $\left|\mathcal{T}_{3}\right|=\left|\mathcal{T}^{\prime}\right|\left|\mathcal{T}^{\prime \prime}\right|$

Bukti:

Karena $S=S^{\prime} \cup\left\{S_{n}\right\}$ himpunan tak kosong dengan $|S|=n=r+t$, maka $S$ memiliki himpunan bagian berupa himpunan kosong dan himpunan tak kosong serta dapat di definisikan suatu topologi pada $S$.

Di definisikan $T_{3}=\left[\begin{array}{cc}M\left(\mathcal{T}^{\prime}\right) & 0 \\ 0 & M\left(\mathcal{T}^{\prime \prime}\right)\end{array}\right]$ matriks berukuran $n \times n$, maka $T_{3}$ merupakan matriks yang di partisi yang terdiri dari $T_{11}=M\left(\mathcal{T}^{\prime}\right), T_{12}$ matriks nol $(r \times t), T_{21}$ matriks nol $(t \times r)$ dan $T_{22}=$ $M\left(\mathcal{T}^{\prime \prime}\right)$. Karena $M\left(\mathcal{T}^{\prime}\right)$ dan $M\left(\mathcal{T}^{\prime \prime}\right)$ masing-masing merupakan matriks refleksif dan $M\left(\mathcal{T}^{\prime}\right)^{2}=$ $M\left(\mathcal{T}^{\prime}\right) ; M\left(\mathcal{T}^{\prime \prime}\right)^{2}=M\left(\mathcal{T}^{\prime \prime}\right)$, maka $T_{3}$ matriks keterhubungan langsung topologi pada $S$.

Diambil $T_{3}=M\left(\mathcal{T}_{3}\right)$, karena $T_{3}$ matriks keterhubungan langsung topologi pada $S$, maka $M\left(\mathcal{T}_{3}\right)$ matriks keterhubungan langsung topologi $\mathcal{T}_{3}$ pada $S$. Jadi, ada topologi $\mathcal{T}_{3}$ pada $S$.

Karena $M\left(\mathcal{T}_{3}\right)$ matriks keterhubungan langsung topologi $\mathcal{T}_{3}$ pada $S$, maka setiap kolom dari $M\left(\mathcal{T}_{3}\right)$ merupakan fungsi karakteristik himpunan terbuka terkecil $B_{j}$ yang memuat $S_{j}$, untuk setiap $s_{j} \in S$. Sehingga banyaknya elemen $\mathcal{T}_{3}$ sama dengan hasil kali dari banyaknya elemen $\mathcal{T}^{\prime}$ dan $\mathcal{T}^{\prime \prime}$. Jadi, $\left|\mathcal{T}_{3}\right|=\left|\mathcal{T}^{\prime}\right|\left|\mathcal{T}^{\prime \prime}\right|$.

Dari 1, 2, dan 3 maka Teorema 2 terbukti.

\section{Contoh 3:}

Diberikan himpunan hingga $E^{\prime}=\{1,2,3,4\}$ dan $\mathcal{T}^{\prime}$ topologi yang didefinisikan pada $E^{\prime}$ dengan $\mathcal{T}^{\prime}=$ $\left\{E^{\prime}, \emptyset,\{1,2\}\right\}$ maka $\left|\mathcal{T}^{\prime}\right|=3$.

1. Misalkan himpunan hingga $E=E^{\prime} \cup\{5\}$ dan $\mathcal{T}_{1}$ topologi yang di definisikan pada $E$ dengan $\mathcal{T}_{1}=$ $\left\{E^{\prime}, \emptyset,\{1,2\}\right\}$ maka $\left|\mathcal{T}_{1}\right|=3$. Jadi, $\left|\mathcal{T}^{\prime}\right|=\left|\mathcal{T}_{1}\right|=3$.

2. Misalkan $\mathcal{T}_{2}=\{E, \emptyset,\{1,2,5\},\{5\}\}$ topologi yang di definisikan pada himpunan hingga $E$, maka $\left|\mathcal{T}_{2}\right|=4=\left|\mathcal{T}^{\prime}\right|+1$.

3. Himpunan hingga $E=\{1,2,3,4,5\}$ dapat dituliskan menjadi $E=\{1,2,3,4\} \cup\{5\}=E^{\prime} \cup\{5\}$ maka $|E|=4+1=5$.

Misalkan $\mathcal{T}^{\prime}$ merupakan topologi pada $E^{\prime}$ dengan $\mathcal{T}^{\prime}=\left\{E^{\prime}, \emptyset,\{1,2\}\right\}$ dan $\mathcal{T}^{\prime \prime}$ merupakan topologi pada $\{5\}$ dengan $\mathcal{T}^{\prime^{\prime}}=\{\{5\}, \emptyset\}$ maka ada $\mathcal{T}_{3}=\{E, \emptyset,\{1,2\},\{5\},\{1,2,5\},\{1,2,3,4\}\}$ topologi yang didefinisikan pada $E$ dan $\left|\mathcal{T}_{3}\right|=\left|\mathcal{T}^{\prime}\right|\left|\mathcal{T}^{\prime \prime}\right|=6$. 


\section{SIMPULAN}

Diberikan suatu himpunan hingga $S$ dengan kardinalitas $n$. Jika $\mathcal{T}$ topologi pada $S$, maka kardinalitas dari $\mathcal{T}$ yang dinotasikan dengan $|\mathcal{T}|$ menyatakan banyaknya elemen dari $\mathcal{T}$. Selain itu, kardinalitas dari $\mathcal{T}$ juga dapat dicari melalui matriks keterhubungan langsung $M(\mathcal{T})$ yang berukuran $n \times n$. Matriks $M(\mathcal{T})$ merupakan matriks 01 yang memenuhi sifat refleksif dan transitif pada operasi Aljabar Boolean.

Pada bahasan ini hanya terbatas pada matriks keterhubungan langsung topologi dan beberapa sifatnya. Terdapat materi matriks insidensi dan topologi pembangun yang tidak di bahas dalam artikel ini.

\section{REFERENSI}

Anton, Howard. 1998. Aljabar Linear Elementer. Jakarta: Gramedia

Gallian, Joseph A.. 1990. Contemporary Abstract Algebra. New York: Addison - Wesley Publishing Company.

Jr. H. Sharp. (1966). Quasy Orderings and Topologies on Finite Sets. Journal of Proceeding American Mathematics Society 17. Diambil dari http://www.jstor.org

Jr. H. Sharp. (1968). Cardinality of Finite Topologies. Journal of Combinatorial Theory 5. Diambil dari http://www.sciencedirect.com

Juniati, Dwi. 2003. Topologi. Surabaya: Usaha Jurusan Matematika UNESA.

Liu, Gui Long. (2005). Rough Sets Over The Boolean Algebra. International Journal of Computer and Information Sciences II. Diambil dari http://www.googlebook.com

Parchmann, Rainer. (1975). On The Cardinalities of Finite Topologies. Journal of Discrete Mathematics II. Di ambil dari http://www.sciencedirect.com

R.P. Stanley. (1971). On The Number of Open Sets. Journal of Combinatorical Theory 10. Dambil dari http://www.sciencedirect.com 